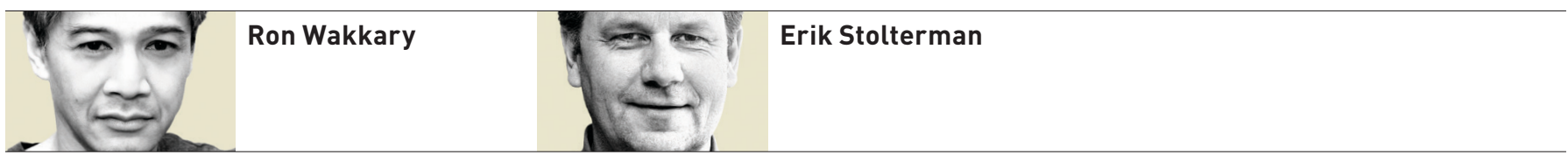

\title{
Felt Experiences
}

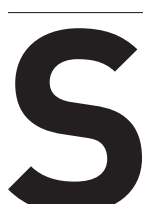

omaesthetics is the acknowledgement that it is through our bodies that we interact with and experience the world. Based on the work of philosopher Richard Shusterman, somaesthetics brings together soma, the body, with aesthetics, our sensory appreciations, to emphasize how our bodily movements influence our ways of being and thinking. In this issue's cover story, Kristina Höök, Anna Ståhl, Martin Jonsson, Johanna Mercurio, Anna Karlsson, and Eva-Carin Banka Johnson introduce these ideas by detailing their own somaesthetic design practices. The authors describe compelling and intriguing design cases, and set the outlines for the challenges ahead for somaesthetic design, including how it can productively inform current assumptions of HCI and interaction design.

Tom Erickson's fascinating piece on creating kairos marks the last entry for Interactions' Social Media forum. We would like to thank Shelly Farnham, who has been the forum editor for Social Media since the July-August 2013 issue. Shelly and her predecessors have helped us explore social media and HCI in the pages of Interactions - her insights and perspectives have made a valuable contribution.

July-August is certainly the "summer issue," and many may be reading this on the beach or while on holiday. We urge you to keep connected with us at Interactions through print, online, or through all things social media - and hope that doing so will enhance your summer relaxation! We value your feedback on articles and welcome your contributions through the many departments within the magazine, including short opinion pieces in Confessions, new and novel prototypes in Demo Hour, targeted articles submitted to our forums, or feature articles and cover stories. And of course, on the heels of our Special Topic on pictorials, we invite you to contribute your photographs to the Visual Thinking Gallery. Visit our website for the submission guidelines and process: http://interactions.acm. org/submissions

Ron Wakkary and Erik Stolterman eic@interactions.acm.org

\section{Somaesthetics emphasizes how our bodily movements influence our ways of being and thinking.}

